\title{
Prognostic Factors of Liver Resection for Large Hepatocellular Carcinoma in Cirrhotic Patients
}

\author{
H.S.Elnaggar ${ }^{1}$, M.M.Rezk ${ }^{2}$, A.H.Abdelmaksod ${ }^{2}$, A.A.Mostafa ${ }^{3}$ and H.E.Ali ${ }^{2}$ \\ ${ }^{1}$ General Surgery, Dept., Faculty of Medicine, Shebin Elkom Univ., Shebin Elkom, Egypt \\ ${ }^{2}$ General Surgery, Dept.,Faculty of Medicine, Benha Univ., Benha, Egypt \\ ${ }^{3}$ Hepatobiliary and Pancreatic Surgery, Dept., National Liver Institute, Menoufia Univ., Menoufia, Egypt \\ E-Mail: drhossamsbry@gmail.com
}

\begin{abstract}
Background: Prognostic modeling in hepatocellular carcinoma patients has a high complexity and should consider 4 tightly related aspects; tumor stage, degree of liver function impairment, patient's general condition and treatment efficacy Objectives: The aim of this study was to determine the different prognostic factors of liver resection for large hepatocellular carcinoma in cirrhotic patients. Patients and Methods: In this retrospective cohort study, 65 cirrhotic patients had liver resection for large hepatocellular carcinoma in the period from January 2015 until December 2019, at National liver institute, Menoufia University and Benha Faculty of Medicine, Benha University. The recurrence and survival data along with patients' data were recorded to identify potential prognostic factors in those patients. Results: Recurrence had occurred in 33 patients (52.38\%) while mortality occurred in 15 patients (23.1\%). Findings on upper endoscope, the site and size of the tumors, the preoperative AJCC stages and pathological grade of tumors affected the recurrence significantly ( $\mathrm{p} 0.015,0.001,<0.001,0.035$ and $<0.001$, respectively) while the preoperative serum albumin, the presence of vascular invasion and Barcelona class affected mortality significantly (p 0.002, 0.002 and 0.024 , respectively). By multivariate analysis, the mean size of HCC and the pathological grade of tumor were the most significant factors that affected the recurrence while the presence of portal vein invasion by the tumor was the most significant factor that affected the survival. Conclusion: Findings on upper endoscope, the site and size of the tumors, the preoperative AJCC stages and pathological grade of tumors were independently associated with recurrence while preoperative serum albumin, the presence of vascular invasion and Barcelona class were associated with survival. On multivariate analysis, the mean size of $\mathrm{HCC}$ and the pathological grade were the most significant factors affected the recurrence while the presence of vascular invasion was the most significant factors that affect the survival.
\end{abstract}

Keywords: Prognostic factors, liver resection, HCC in liver cirrhosis.

\section{Introduction}

Hepatocellular carcinoma (HCC) represents the fifth most common cancer and the third most common cause of cancer death, behind only lung and stomach cancer. HCC accounts for the majority of these primary cancers of the liver. Despite even aggressive surgical approaches, most patients who have HCC or liver disease are advanced to permit treatment with "curative" intent [1].

The prognosis of cancer patients is solely related to tumor stage. However, this is not the case in HCC patients. Cirrhosis underlies the neoplasm in most individuals and thus, their outcome is related to these two entities that simultaneously determine the applicability and efficacy of treatments. Accordingly, prognostic modeling in HCC patients has a high complexity and should consider 4 tightly related aspects: tumor stage, degree of liver function impairment, patient's general condition, and treatment efficacy [2].

Prognostic systems assessing just one of these aspects (Child-Pugh classification, TNM stage, performance status) have a marginal usefulness. The Okuda staging based on bilirubin, albumin, ascites, and tumor burden has been used for years, but it is unable to distinguish between early and advanced HCC and mostly serves to identify end-stage individuals [3].
The aim of this study was to determine the different prognostic factors of liver resection for large hepatocellular carcinoma in cirrhotic patients.

\section{Patients and Methods}

This was a retrospective cohort study to analyze the different prognostic values after liver resection of large hepatocellular carcinoma in cirrhotic patients in the period from January 2015 until December 2019, at National liver institute, Menoufia University and Benha Faculty of Medicine, Benha University.

After a primary review of all patients' records from clinic files, operative notes, pathology records, laboratory evaluations and other imaging studies in the allocated period, the data of 65 patients were found to be eligible to be included in the study. The collected data were demographic data including age, sex and previous history of medical disease, preoperative data including laboratory results, radiology results, results of upper endoscopy and preoperative AJCC staging and Child and MELD score, operative data including type of operation and type and method of resection, postoperative data and results of follow-up.

Data were collected and entered to the computer using SPSS (Statistical Package for Social Science) program version 26.0, SPSS Inc., Chicago, Illinois, USA for statistical analysis. Descriptive statistics was expressed as mean, SD and range in quantitative data and as frequency and percentage in qualitative analysis. Analytical statistics was done by using Chi- 
square test for qualitative data, Student t-test for quantitative data, Kaplan-Meier survival analysis and multiple logistic regression analysis for multivariate analysis. P (probability) value was considered statistically significant if it was less than 0.05 .

\section{Results}

In this study, 2 patients died in the early postoperative period while recurrence had occurred in 33 patients (52.38\%). According to recurrence data in the remaining 63 patients, Table 1 shows the difference among the patients (Table 1). Findings on upper endoscope, the site and size of the tumors, the preoperative AJCC stages and pathological grade of tumors differed significantly between both groups (p0.015, 0.001, <0.001, 0.035 and $<0.001$, respectively). By multivariate analysis, the mean size of HCC and the pathological grade were the most significant factors that affect the recurrence among the patients included in the study. Table (1)

In this study, mortality occurred in 15 patients (23.1\%). According to survival data, Table 2 shows the difference among the patients (Table 2). The preoperative serum albumin, the presence of vascular invasion and Barcelona class differ significantly between both groups (p 0.002, 0.002 and 0.024 , respectively). By multivariate analysis, the presence of portal vein invasion by the tumor was the most significant factor that affects the survival among the patients included in the study. Table (2)

Table (1) Data of the patients according to recurrence (N=65)

\begin{tabular}{|c|c|c|c|}
\hline Data & $\begin{array}{c}\text { No Recurrence group } \\
(\mathbf{N}=\mathbf{3 0})\end{array}$ & $\begin{array}{l}\text { Recurrence group } \\
(\mathbf{N}=33)\end{array}$ & p value \\
\hline Age (Years) & $\begin{array}{c}56.9 \pm 6.62 \\
(45-70)\end{array}$ & $\begin{array}{c}58.27 \pm 6.21 \\
\quad(42-70)\end{array}$ & $0.401 \wedge$ \\
\hline Male Gender & $28(93.33 \%)$ & $28(84.85 \%)$ & $0.285 \#$ \\
\hline Positive Medical History & $27(90 \%)$ & $33(100 \%)$ & $0.063 \#$ \\
\hline Hepatitis B virus & $2(6.67 \%)$ & $1(3.03 \%)$ & $0.498 \#$ \\
\hline Hepatitis C virus & $27(90 \%)$ & $33(100 \%)$ & $0.063 \#$ \\
\hline Diabetes Mellitus & $6(20 \%)$ & $6(18.18 \%)$ & $0.859 \#$ \\
\hline Hypertension & $3(10 \%)$ & $6(18.18 \%)$ & $0.354 \#$ \\
\hline Serum Bilirubin & $0.95 \pm 0.33$ & $0.99 \pm 0.45$ & $0.660^{\wedge}$ \\
\hline $\begin{array}{l}\text { Serum Albumin } \\
(\mathrm{g} / \mathrm{dl})\end{array}$ & $\begin{array}{c}3.37 \pm 0.58 \\
(2.4-4.3)\end{array}$ & $\begin{array}{c}3.34 \pm 0.55 \\
(2-4.4)\end{array}$ & $0.848^{\wedge}$ \\
\hline Prothrombin Concentration (\%) & $\begin{array}{c}90.93 \pm 10.60 \\
(70-100)\end{array}$ & $\begin{array}{l}85.03 \pm 14.29 \\
\quad(40-100)\end{array}$ & $0.066^{\wedge}$ \\
\hline $\begin{array}{l}\text { Serum Creatinine } \\
(\mathrm{mg} / \mathrm{dl})\end{array}$ & $\begin{array}{l}0.82 \pm 0.2 \\
(0.4-1.2)\end{array}$ & $\begin{array}{l}0.84 \pm 0.18 \\
(0.46-1.3)\end{array}$ & $0.641^{\wedge}$ \\
\hline $\begin{array}{l}\text { Alpha Feto-protein } \\
(\mathrm{ng} / \mathrm{ml})\end{array}$ & $\begin{array}{c}1127.42 \pm 2362.78 \\
(2.7-9071)\end{array}$ & $\begin{array}{c}48.04 \pm 786.95 \\
(4.7-4276)\end{array}$ & $0.166^{\wedge}$ \\
\hline $\begin{array}{l}\text { Carcinoembryonic } \\
(\mathrm{ng} / \mathrm{ml})\end{array}$ & $\begin{array}{c}6.31 \pm 7.74 \\
(0-23)\end{array}$ & $\begin{array}{l}9.14 \pm 8.16 \\
(0-27)\end{array}$ & $0.164^{\wedge}$ \\
\hline Normal upper endoscope & $19(63.33 \%)$ & $27(81.82 \%)$ & $0.015 \# *$ \\
\hline MELD Score & $\begin{array}{c}7.3 \pm 1.39 \\
(6-10)\end{array}$ & $\begin{array}{l}7.94 \pm 2.22 \\
(6-13)\end{array}$ & $0.173^{\wedge}$ \\
\hline Left Hepatic Mass & $6(20 \%)$ & $21(63.64 \%)$ & $0.001 \# *$ \\
\hline Tumor Size & $\begin{array}{l}6.2 \pm 2.59 \\
\quad(5-9)\end{array}$ & $\begin{array}{c}10.7 \pm 3.33 \\
(8-11)\end{array}$ & $<0.001 \wedge *$ \\
\hline Single tumor & $29(96.67 \%)$ & $28(84.85 \%)$ & $0.110 \#$ \\
\hline Preoperative AJCC Stage I & $26(86.67 \%)$ & $19(57.58 \%)$ & $0.035 \# *$ \\
\hline Barcelona Class A & $18(60 \%)$ & $12(36.36 \%)$ & $0.131 \#$ \\
\hline Open Resection & $30(100 \%)$ & $32(96.97 \%)$ & $0.336 \#$ \\
\hline Anatomical resection & $2(6.67 \%)$ & $7(21.21 \%)$ & $0.099 \#$ \\
\hline Use of Habib Sealer & $14(46.67 \%)$ & $25(75.76 \%)$ & $0.160 \#$ \\
\hline Use of RFA & $0(0 \%)$ & $3(9.09 \%)$ & $0.182 \#$ \\
\hline Grade III Tumor & $6(20 \%)$ & $24(72.73 \%)$ & $<0.001 \wedge *$ \\
\hline Portal vein Invasion & $3(10 \%)$ & $2(6.06 \%)$ & $0.563 \#$ \\
\hline Involved Surgical Margins & $13(43.33 \%)$ & $11(33.33 \%)$ & $0.414 \#$ \\
\hline
\end{tabular}

Data in mean \pm SD (Range), N(\%) 
Table (2) Data of the patients according to Survival $(\mathrm{N}=65)$.

\begin{tabular}{|c|c|c|c|}
\hline Data & $\begin{array}{c}\text { Survival Group } \\
(\mathbf{N}=\mathbf{5 0})\end{array}$ & $\begin{array}{c}\text { Mortality Group } \\
(\mathrm{N}=15)\end{array}$ & p value \\
\hline Age (Years) & $\begin{array}{c}57.52 \pm 6.39 \\
(45-70)\end{array}$ & $\begin{array}{c}57.8 \pm 6.21 \\
(42-65)\end{array}$ & $0.88^{\wedge}$ \\
\hline Male Gender & $45(90 \%)$ & $13(86.67 \%)$ & 0.715 \# \\
\hline Positive Medical History & $47(94 \%)$ & $15(100 \%)$ & $0.331 \#$ \\
\hline Hepatitis B virus & $2(4 \%)$ & $1(6.67 \%)$ & $0.666 \#$ \\
\hline Hepatitis $\mathrm{C}$ virus & $47(94 \%)$ & $15(100 \%)$ & $0.331 \#$ \\
\hline Diabetes Mellitus & $6(20 \%)$ & $6(18.18 \%)$ & 0.205 \# \\
\hline Hypertension & $3(10 \%)$ & $6(18.18 \%)$ & $0.572 \#$ \\
\hline $\begin{array}{l}\text { Serum Bilirubin } \\
(\mathrm{mg} / \mathrm{dl})\end{array}$ & $\begin{array}{c}0.94 \pm 0.39 \\
(0.2-2.3)\end{array}$ & $\begin{array}{c}1.12 \pm 0.39 \\
(0.4-1.8)\end{array}$ & $0.111^{\wedge}$ \\
\hline $\begin{array}{l}\text { Serum Albumin } \\
(\mathrm{g} / \mathrm{dl})\end{array}$ & $\begin{array}{c}3.48 \pm 0.48 \\
(2.4-4.3)\end{array}$ & $\begin{array}{c}2.9 \pm 0.57 \\
(2-4.4)\end{array}$ & $0.002 \wedge *$ \\
\hline $\begin{array}{l}\text { Prothrombin Concentration } \\
(\%)\end{array}$ & $\begin{array}{l}89.44 \pm 10.95 \\
(70-100)\end{array}$ & $\begin{array}{c}79.8 \pm 17.54 \\
(40-100)\end{array}$ & $0.06^{\wedge}$ \\
\hline $\begin{array}{l}\text { Serum Creatinine } \\
(\mathrm{mg} / \mathrm{dl})\end{array}$ & $\begin{array}{l}0.84 \pm 0.18 \\
(0.46-1.3)\end{array}$ & $\begin{array}{c}0.8 \pm 0.19 \\
(0.4-1.09)\end{array}$ & $0.514^{\wedge}$ \\
\hline $\begin{array}{l}\text { Alpha Feto-protein } \\
(\mathrm{ng} / \mathrm{ml})\end{array}$ & $\begin{array}{c}863.78 \pm 1936.8 \\
(2.7-9071)\end{array}$ & $\begin{array}{l}508.3 \pm 504.09 \\
(1.5-1420)\end{array}$ & $0.246^{\wedge}$ \\
\hline $\begin{array}{l}\text { Carcinoembryonic Antigen } \\
(\mathrm{ng} / \mathrm{ml})\end{array}$ & $\begin{array}{l}7.39 \pm 8.48 \\
(0-27)\end{array}$ & $\begin{array}{l}9.72 \pm 7.01 \\
\quad(1-23)\end{array}$ & $0.291^{\wedge}$ \\
\hline Normal upper endoscope & $35(70 \%)$ & $11(73.33 \%)$ & $0.071 \#$ \\
\hline MELD Score & $\begin{array}{l}7.52 \pm 1.67 \\
(6-13)\end{array}$ & $\begin{array}{l}8.27 \pm 2.46 \\
(6-13)\end{array}$ & $0.286^{\wedge}$ \\
\hline Left Hepatic Mass & $25(50 \%)$ & $3(20 \%)$ & $0.110 \#$ \\
\hline Tumor Size & $\begin{array}{l}8.28 \pm 4.02 \\
(5-11)\end{array}$ & $\begin{array}{l}9.07 \pm 2,52 \\
(5-11)\end{array}$ & $0.368^{\wedge} *$ \\
\hline Single tumor & $46(92 \%)$ & $13(86.67 \%)$ & $0.531 \#$ \\
\hline Preoperative AJCC Stage I & $38(76 \%)$ & $9(60 \%)$ & $0.115 \#$ \\
\hline Barcelona Class A & $27(54 \%)$ & $5(33.33 \%)$ & $0.024 \# *$ \\
\hline Open Resection & $49(98 \%)$ & $15(100 \%)$ & $0.581 \#$ \\
\hline Anatomical resection & $7(14 \%)$ & $2(13.33 \%)$ & $0.984 \#$ \\
\hline Use of Habib Sealer & $29(58 \%)$ & $11(73.33 \%)$ & 0.636 \# \\
\hline Use of RFA & $3(6 \%)$ & $0(0 \%)$ & $0.654 \#$ \\
\hline Grade III Tumor & $22(44 \%)$ & $10(66.67 \%)$ & $0.270^{\wedge}$ \\
\hline Portal vein Invasion & $1(2 \%)$ & $4(26.67 \%)$ & $0.002 \# *$ \\
\hline Involved Surgical Margins & $17(34 \%)$ & $7(46.67 \%)$ & $0.373 \#$ \\
\hline
\end{tabular}

Data in mean \pm SD (Range), N(\%)

$\wedge$ Student $\mathrm{t}$ test \# Chi-Square test

* Statistically Significant

\section{Discussion}

Hepatocellular carcinoma recurrence is divided into early recurrence (less than 2 years) and late recurrence (more than 2 years) according to the time to recurrence after surgery. Early recurrence within 2 years after surgery is most likely the consequence of occult metastasis from the initial tumor, whereas late recurrence after 2 years post surgery is often of clonal origin, which is different from the original tumor, suggesting a de novo second primary HCC [4].

In this study, recurrence had occurred in 33 patients $(52.38 \%)$. at resection site in 5 patients (7.94\%), at other segments in 28 patients $(44.44 \%)$ and at distant areas in 6 patients $(9.52 \%)$. In $\mathrm{Xu}$ and colleagues study (2019), recurrence occurred in $41.3 \%$ of the 734 patients. In 303 patients with late recurrence, $273(90.1 \%)$ had intrahepatic recurrence only, $30(9.9 \%)$ had both intrahepatic and extrahepatic recurrence, and none had extrahepatic recurrence only [4].

In this study, findings on upper endoscope, the site and size of the tumors, the preoperative AJCC stages and pathological grade of tumors affected the recurrence ( $\mathrm{p} 0.015,0.001,<0.001,0.035$ and $<0.001$, respectively). By logistic regression multivariate analysis, the mean size of HCC and the pathological grade were the most significant factors. In $\mathrm{Xu}$ and colleagues study (2019), Male sex, cirrhosis, multiple tumors, satellite nodules, tumor size greater than $5 \mathrm{~cm}$, and macroscopic and microscopic vascular invasion were independent risk factors of recurrence [4].

The definition of perioperative mortality in most published studies was death in hospital or death within 30 days after the operation. Recent studies reported perioperative mortality rates of $2.6 \%$ to $8.4 \%$ for HCC patients undergoing major liver resection. In this 
study, postoperative mortality occurred in 2 patients (3.08\%); one at the first postoperative day and the other after 12 days. In Lee and colleagues study (2016), the 30-day mortality rate was $1.8 \%$ [5].

In this study, the preoperative serum albumin, the presence of vascular invasion and Barcelona class

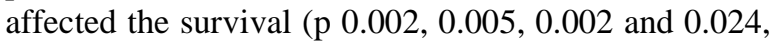
respectively). By logistic regression multivariate analysis, the presence of portal vein invasion by the tumor was the most significant factor. In Lee and colleagues study (2016), they found that diabetes mellitus, hypoalbuminemia, high AFP, massive blood loss, and major surgical procedure are independently associated with early mortality for patients undergoing liver resection [5].

\section{Conclusion}

Findings on upper endoscope, the site and size of the tumors, the preoperative AJCC stages and pathological grade of tumors were independently associated with recurrence while preoperative serum albumin, the presence of vascular invasion and Barcelona class were associated with survival. On multivariate analysis, the mean size of HCC and the pathological grade were the most significant factors affected the recurrence while the presence of vascular invasion was the most significant factors that affect the survival.

\section{References}

[1] J.Marrero, L.Kulik, C.Sirlin, A.Zhu, R.Finn, M.Abecassis. Diagnosis, Staging, and Management of Hepatocellular Carcinoma: 2018 Practice Guidance by the American Association for the Study of Liver Diseases. Hepatology .vol.8,pp.723-50.2018.

[2] W.Rashed, M.Kandeil, M.Mahmoud, S.Ezzat. Hepatocellular Carcinoma (HCC) in Egypt: A comprehensive overview. J Egypt Natl Canc Inst.vol.32,pp.5,2020.

[3] S.Karademir. Staging of hepatocellular carcinoma. Hepatoma Res .vol.4,pp.58,2018.

[4] X.Xu, H.Xing, J.Han, Z.Li, W.Lau, Y.Zhou. Risk Factors, Patterns, and Outcomes of Late Recurrence After Liver Resection for Hepatocellular Carcinoma: A Multicenter Study From China. JAMA Surg .vol.154(3),pp.20917,2019 .

[5] C.Lee, H.Tsai, C.Sung, C.Chen, S.Huang, W.Jeng. Risk factors for early mortality after hepatectomy for hepatocellular carcinoma. Medicine (Baltimore) .vol. 95(39),pp.e5028,2016. 